\title{
A Model for Computing Gap Energy and Electron Affinity Energy of Carbon Nanostructures
}

\author{
Ali Asghar Khakpoor*, Bahare Agahi Keshe \\ Department of Physics, Islamic Azad University, Central Tehran Branch (IAUCTB), Iran
}

Copyright $(2016$ by authors, all rights reserved. Authors agree that this article remains permanently open access under the terms of the Creative Commons Attribution License 4.0 International License

\begin{abstract}
Molecular electronic, which is supposed to replace silicon electronic in the future, is an incipient branch of Nanotechnology which focusing on the organic molecules. Since recognizing and examining this family of nano-structures needs long time and very expensive, an appropriate pattern to predict electronic properties is very beneficial; Topological Indices Method (TIM) is a useful approach for this purpose. Therefore, it is first tried to produce a relationship between the topological indices based on the number of rings; then the ISI index values are calculated for Circumacenes family. The gap energy and electron affinity energy of Circumacenes family $\left(\mathrm{C}_{8(\mathrm{n}+2) / 3} \mathrm{H}_{(2 \mathrm{n}+22) / 3}\right)$ were calculated using Gaussian 09 software and compared to the validated results from experiments and other references. The opto-electronics properties of Circumacenes family were described by ISI index. Finally, some heavier members of Circumacenes family are exposed to TIM method to predict of energy gap, and electron affinity energy.
\end{abstract}

Keywords Molecular Electronic, Carbon Nanostructures, Circumacenes, Gap Energy, Electron Affinity

\section{Introduction}

Today's knowledge requires increasing the capacity of data restoration, data transition, and making electronic components as small as possible; the electronic components' being smaller not only increases the speed of the process, but also reduces the amount of consumed energy, two important goals which are accessible through Nano-electronic technique. The electronic industry is based on silicon is 50 years old and has gradually matured technologically, industrially, and financially. Molecular electronic, which is supposed to replace silicon electronic in the future, is an incipient branch of Nano-technology. Since minifying the size of electronic components on Nano-scale confronts various limitations, focusing on the molecular electronic is a considerable point which should attract attention. The molecular electronic is a branch of science based on Nano-technology with multiple applications in electronic industry in which organic molecules are central. Aromatic hydrocarbon from the root of benzene can provide suitable environments for electron transition due to $\mathrm{p}$ orbitals, upper and lower electron clouds, and resonance phenomenon. Electronic circuits and logic gates are designed out of the joining of these hydrocarbons [1-4].

Circumacenes is a family of organic molecules with the chemical formula of $\mathrm{C}_{8(\mathrm{n}+2) / 3} \mathrm{H}_{(2 \mathrm{n}+22) / 3}$ which is focused in molecular electronic [5-6]. Since recognizing and examining this family of Nano-structures needs huge time and money, an appropriate pattern to predict electronic features is very beneficial; Topological Indices Method (TIM), is a cheap and useful approach to gain this goal [7-13]. A single number, representing a chemical structure in graph-theoretical terms via the molecular graph, is called a topological descriptor and if it in addition correlates with a molecular property it is called topological index; it is used to understand physicochemical properties of chemical compounds. Topological indices are interesting since they capture some of the properties of a molecule in a single number. Hundreds of topological indices have been introduced and studied, starting with the work by Wiener in which he used the sum of all shortest-path distances of a (molecular) graph for modeling physical properties of alkanes [14].

\section{Materials and Methods}

\subsection{Definition}




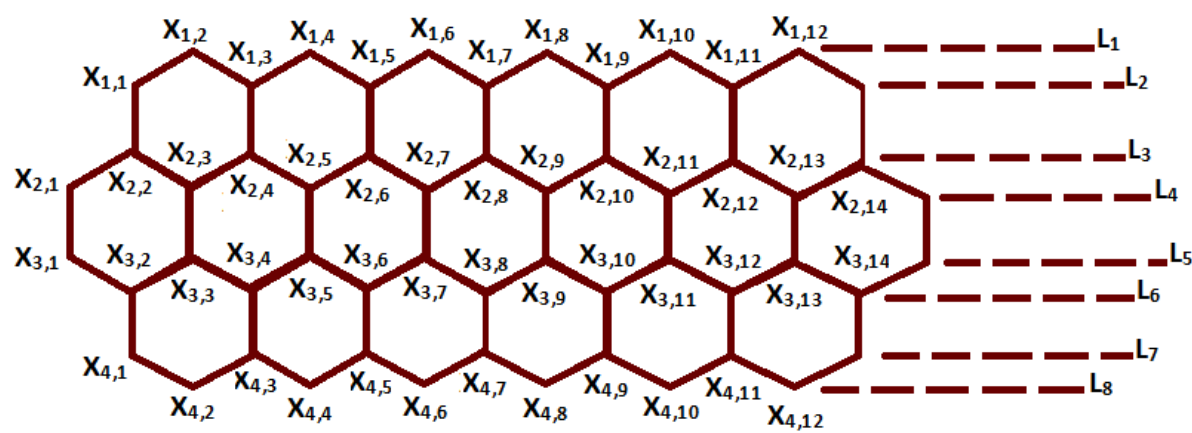

Figure 1. Simple molecular graph of Circumacenes $\left(\mathrm{C}_{(8 \mathrm{n}+16) / 3} \mathrm{H}_{(2 \mathrm{n}+22) / 3}\right)$.

In mathematical, a non-empty set of objects identified as vertices $(\mathrm{V})$ is called a graph. This vertices are connected by lines called edge (E), and are showed as $G=G(V, E)$. A molecular graph is a simple graph whose vertices are composed from the atoms of a molecule, and bonds between atoms of the molecule make up edges of the graph. In chemical graphs hydrogen atoms are removed, and they are discarded. Dehydrogenized graph is said to these graphs in phrase. As well as all bonds between the atoms are considered as unique, and the degree of each vertex will be 4 maximally [15-16]. One of the topological indices is ISI index which is defined as (1) [17]:

$$
\operatorname{ISI}(G)=\sum_{u v \in E(G)} \frac{1}{\frac{1}{d_{u}}+\frac{1}{d_{v}}}=\sum_{u v \in E(G)} \frac{d_{u} d_{v}}{d_{u}+d_{v}}
$$

Where $d_{u}$ and $d_{v}$ are degrees of $u$ and $v$ vertices, respectively, and they have a common bond together.

\subsection{Methods}

It is first tried to produce a relationship between the topological indices based on the number of rings; then ISI index values are calculated for some members of Circumacenes family. Consider simple graph of Circumacenes family $\left(\mathrm{C}_{(8 n+16) / 3} \mathrm{H}_{(2 n+22) / 3}\right)$ as presented in Figure 1.

Theorem 1: Suppose $\mathrm{n}$ is the number of rings in Circumacenes family; therefore ISI index equals to:

$$
\operatorname{ISI}(G)=\frac{61 n+53}{15}
$$

Proof: Imagine a simple molecular graph which can be explicated from nine areas:

I. All vertices and edges that are located between $\mathrm{L}_{1}$ and $\mathrm{L}_{2}$ levels and it is called $\mathrm{G}_{1}$.

II. All vertices and edges that are located between $\mathrm{L}_{2}$ and $\mathrm{L}_{3}$ levels and it is called $\mathrm{G}_{2}$.

III. All vertices and edges that are located between $\mathrm{L}_{3}$ and $\mathrm{L}_{4}$ levels and it is called $\mathrm{G}_{3}$.

IV. All vertices and edges that are located between $\mathrm{L}_{4}$ and $\mathrm{L}_{5}$ levels and it is called $\mathrm{G}_{4}$.

V. All vertices and edges that are located between $L_{5}$ and $\mathrm{L}_{6}$ levels and it is called $\mathrm{G}_{5}$.

VI. All vertices and edges that are located between $\mathrm{L}_{6}$ and $\mathrm{L}_{7}$ levels and it is called $\mathrm{G}_{6}$.

All vertices and edges that are located between $\mathrm{L}_{7}$ and $\mathrm{L}_{8}$ levels and it is called $\mathrm{G}_{7}$.

For $\mathrm{G}_{1}$, using (1), we have:

$$
\operatorname{ISI}\left(G_{1}\right)=\sum_{m=1}^{k-1} \frac{d_{1, m} d_{1, m+1}}{d_{1, m}+d_{1, m+1}}
$$

The first and last terms are separated:

$$
\begin{aligned}
& \operatorname{ISI}\left(G_{1}\right)=\sum_{m=1}^{k-1} \frac{d_{1, m} d_{1, m+1}}{d_{1, m}+d_{1, m+1}}=\frac{d_{1,1} d_{1,2}}{d_{1,1}+d_{1,2}}+ \\
& +\frac{d_{1, k-1} d_{1, k}}{d_{1, k-1}+d_{1, k}}+\sum_{m=2}^{k-2} \frac{d_{1, m} d_{1, m+1}}{d_{1, m}+d_{1, m+1}}
\end{aligned}
$$

And for the first two terms in (4) we have

$$
\frac{d_{1,1} d_{1,2}}{d_{1,1}+d_{1,2}}=\frac{d_{1, k-1} d_{1, k}}{d_{1, k-1}+d_{1, k}}=1
$$

And for $\mathrm{m} \neq 1$ and $\mathrm{m} \neq \mathrm{k}$ we will have:

$$
\frac{d_{1, m} d_{1, m+1}}{d_{1, m}+d_{1, m+1}}=\frac{6}{5}
$$

And though (5) and (6), we can conclude:

$$
\operatorname{ISI}\left(G_{1}\right)=1+1+\sum_{m=2}^{k-2} \frac{6}{5}=2+\frac{6}{5}(k-3)
$$

And since $\mathrm{k}=(2 \mathrm{n}+1) / 3$, therefore:

$$
\operatorname{ISI}\left(G_{1}\right)=2+\frac{6}{5}\left(\frac{2 n-8}{3}\right)
$$

In $\mathrm{G}_{2}$, first we separate first and last terms:

$$
\begin{aligned}
& \operatorname{ISI}\left(G_{2}\right)=\sum_{m=1}^{k} \frac{d_{1, m} d_{2, m}}{d_{1, m}+d_{2, m}}=\frac{d_{1,1} d_{2,1}}{d_{1,1}+d_{2,1}}+ \\
& +\frac{d_{1, k} d_{2, k}}{d_{1, k}+d_{2, k}}+\sum_{m=2}^{k-1} \frac{d_{1, m} d_{2, m}}{d_{1, m}+d_{2, m}}
\end{aligned}
$$


Equation (9) signifies for the first two terms as:

$$
\frac{d_{1,1} d_{2,1}}{d_{1,1}+d_{2,1}}=\frac{d_{1, k} d_{2, k}}{d_{1, k}+d_{2, k}}=\frac{6}{5}
$$

And for two terms of $m \neq 1$ and $m \neq k$, we have:

$$
\frac{d_{1, m} d_{2, m}}{d_{1, m}+d_{2, m}}=1
$$

Equations (10) and (11) will lead to:

$$
\operatorname{ISI}\left(G_{2}\right)=\frac{6}{5}+\frac{6}{5}+\sum_{m=2}^{k-1} 1=\frac{12}{5}+(k-2)
$$

And since $\mathrm{k}=(\mathrm{n}+2) / 3$, so:

$$
\operatorname{ISI}\left(G_{2}\right)=2+\frac{6}{5}\left(\frac{n-4}{3}\right)
$$

In $\mathrm{G}_{3}$, first we separate first and last terms:

$$
\begin{aligned}
& \operatorname{ISI}\left(G_{3}\right)=\sum_{m=1}^{k-1} \frac{d_{2, m} d_{2, m+1}}{d_{2, m}+d_{2, m+1}}=\frac{d_{2,1} d_{2,2}}{d_{2,1}+d_{2,2}}+ \\
& +\frac{d_{2, k-1} d_{2, k}}{d_{2, k-1}+d_{2, k}}+\sum_{m=2}^{k-2} \frac{d_{2, m} d_{2, m+1}}{d_{2, m}+d_{2, m+1}}
\end{aligned}
$$

Equation (14) signifies for the first two terms as:

$$
\frac{d_{2,1} d_{2,2}}{d_{2,1}+d_{2,2}}=\frac{d_{2, k-1} d_{2, k}}{d_{2, k-1}+d_{2, k}}=\frac{6}{5}
$$

And for two terms of $m \neq 1$ and $m \neq k$, we have:

$$
\frac{d_{2, m} d_{2, m+1}}{d_{2, m}+d_{2, m+1}}=1
$$

Equations (15) and (16) will lead to:

$$
I S I\left(G_{3}\right)=\frac{6}{5}+\frac{6}{5}+\sum_{m=2}^{k-2} 1=\frac{12}{5}+(k-3)
$$

And since $\mathrm{k}=(2 \mathrm{n}+7) / 3$, so:

$$
\operatorname{ISI}\left(G_{3}\right)=\frac{12}{5}+\left(\frac{2 n-2}{3}\right)
$$

For $\mathrm{G}_{4}$, we can write:

$$
\operatorname{ISI}\left(G_{4}\right)=\sum_{m=1}^{k} \frac{d_{2, m} d_{3, m}}{d_{2, m}+d_{3, m}}
$$

The first and last terms are separated:

$\operatorname{ISI}\left(G_{4}\right)=\frac{d_{2,1} d_{3,1}}{d_{2,1}+d_{3,1}}+\frac{d_{2, k} d_{3, k}}{d_{2, k}+d_{3, k}}+\sum_{m=2}^{k-1} \frac{d_{2, m} d_{3, m}}{d_{2, m}+d_{3, m}}$

And for the first two terms in (20), we have

$$
\frac{d_{2,1} d_{3,1}}{d_{2,1}+d_{3,1}}=\frac{d_{2, k} d_{3, k}}{d_{2, k}+d_{3, k}}=1
$$

And for $\mathrm{m} \neq 1$ and $\mathrm{m} \neq \mathrm{k}$ we will have:

$$
\frac{d_{2, m} d_{3, m}}{d_{2, m}+d_{3, m}}=1
$$

And though (21) and (22), we can conclude:

$$
\operatorname{ISI}\left(G_{4}\right)=1+1+\sum_{m=2}^{k-1} 1=2+(k-2)
$$

And since $\mathrm{k}=(\mathrm{n}+5) / 3$, therefore:

$$
\operatorname{ISI}\left(G_{4}\right)=2+\left(\frac{n-1}{3}\right)
$$

The calculation procedure of $\mathrm{G}_{5}, \mathrm{G}_{6}$ and $\mathrm{G}_{7}$ areas are the same as $\mathrm{G}_{3}, \mathrm{G}_{2}$ and $\mathrm{G}_{1}$ respectively and is given through (18), (10) and (13), Therefore,

$$
\begin{aligned}
& I S I(G)=I S I\left(G_{1}\right)+\operatorname{ISI}\left(G_{2}\right)+\operatorname{ISI}\left(G_{3}\right)+ \\
& +\operatorname{ISI}\left(G_{4}\right)+\operatorname{ISI}\left(G_{5}\right)+\operatorname{ISI}\left(G_{6}\right)+\operatorname{ISI}\left(G_{7}\right)
\end{aligned}
$$

So, (2) is achieved and theorem is proved.

Then ISI index is calculated for some Circumacenes family members using (2) and the results are shown in Table 1.

Table 1. ISI index for the first five members of Circumacenes family

\begin{tabular}{|c|c|c|c|c|}
\hline $\begin{array}{c}\text { Chemical } \\
\text { Formula }\end{array}$ & $\begin{array}{c}\text { IUPAC } \\
\text { Name }\end{array}$ & coronene & ISI \\
\hline $\mathrm{C}_{24} \mathrm{H}_{12}$ & ondex
\end{tabular}

\section{Results}

Electro-optical properties of Circumacenes family $\left(\mathrm{C}_{8(\mathrm{n}+2) / 3} \mathrm{H}_{(2 \mathrm{n}+22) / 3}\right)$ including of gap energy and electron affinity energy, were calculated using Gaussian 09 software and compared to the validated results from experiments and other references as given in Table 2. [18-19]. 
Table 2. Energy gap and electron affinity energy of the first five members of Circumacenes family

\begin{tabular}{|c|c|c|}
\hline Chemical Formula & $\mathrm{E}_{\text {affinity }}(\mathrm{ev})$ & $\mathrm{E}_{\text {gap }}$ (ev) \\
\hline $\mathrm{C}_{24} \mathrm{H}_{12}$ & 0.96 & 3.42 \\
\hline $\mathrm{C}_{32} \mathrm{H}_{14}$ & 1.55 & 2.69 \\
\hline $\mathrm{C}_{40} \mathrm{H}_{16}$ & 1.91 & 2.03 \\
\hline $\mathrm{C}_{48} \mathrm{H}_{18}$ & 2.17 & 1.54 \\
\hline $\mathrm{C}_{56} \mathrm{H}_{20}$ & 2.37 & 1.18 \\
\hline
\end{tabular}

Figures 2 and 3 respectively show gap energy changes and electron affinity energy changes for Circumacenes family according to ISI index as the results of this work.

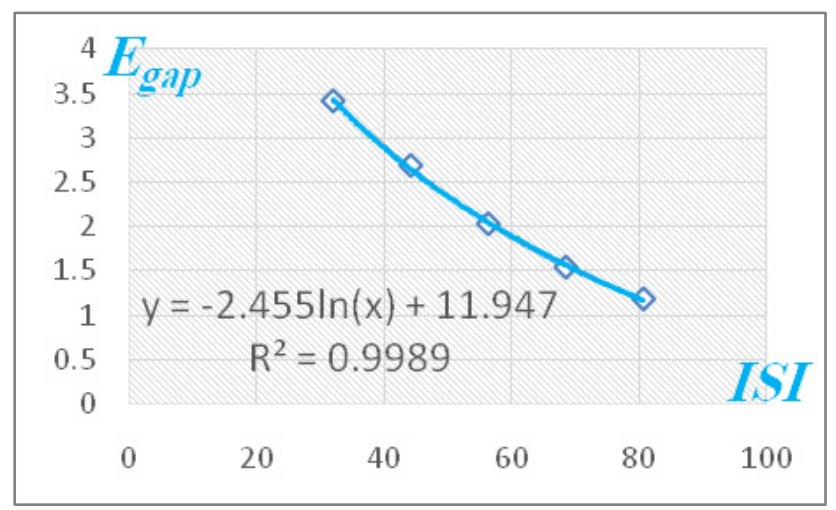

Figure 2. Gap energy changes in Circumacenes family according to ISI index.

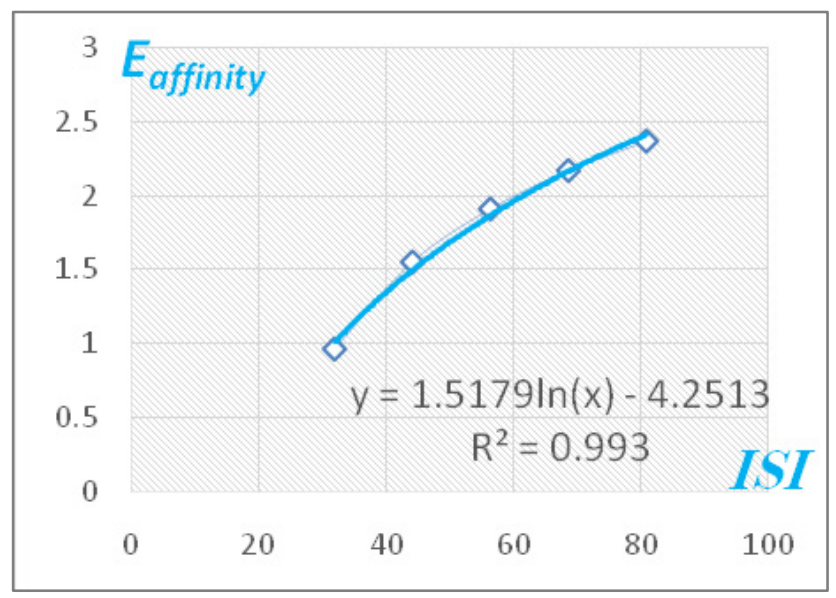

Figure 3. Electron affinity energy changes in Circumacenes family according to ISI index.

As it is shown in Figure 2, the gap energy can calculated via ISI index changes for Circumacenes family, with a high level of precision $\left(\mathrm{R}^{2}=0.9989\right)$. This prediction is possible using (26).

$$
\mathrm{E}_{g}=-2.455 \ln (I S I)+11.947
$$

This predictions have been performed with a precision of $\mathrm{R}^{2}=0.993$ for electron affinity energy, by (27).

$$
E_{\text {affinity }}=1.5179 \ln (I S I)-4.2513
$$

\section{Conclusions}

Table 3 shows the calculation results gap energy and electron affinity energy of Circumacenes family through TIM method. Table 3 shows the validity of TIM method in a comparison of results with the reference values (Table 2).

Table 3. Calculation energy gap and electron affinity energy of Circumacenes family through TIM method

\begin{tabular}{|c|c|c|}
\hline $\begin{array}{c}\text { Chemical } \\
\text { Formula }\end{array}$ & $\begin{array}{c}\mathrm{E}_{\text {affinity }} \\
(\mathrm{ev})\end{array}$ & $\begin{array}{c}\mathrm{E}_{\text {gap }} \\
(\mathrm{ev})\end{array}$ \\
\hline $\mathrm{C}_{24} \mathrm{H}_{12}$ & 1.0093 & 3.4386 \\
\hline $\mathrm{C}_{32} \mathrm{H}_{14}$ & 1.4996 & 2.6456 \\
\hline $\mathrm{C}_{40} \mathrm{H}_{16}$ & 1.8695 & 2.0472 \\
\hline $\mathrm{C}_{48} \mathrm{H}_{18}$ & 2.1668 & 1.5665 \\
\hline $\mathrm{C}_{56} \mathrm{H}_{20}$ & 2.4152 & 1.1646 \\
\hline
\end{tabular}

As it is shown, prediction of some physical and electro-optic properties of Circumacenes family with high precision is possible through TIM method and ISI index. The significance of this method is magnified in the case of heavier elements in article theoretical and experimental methods wasting much time and money still giving approximated results. Hereafter, some heavier members of Circumacenes family are exposed to TIM method. Equations 26 and 27 have been used to predict the energy gap and electron affinity energy. The results are shown in Table 4.

Table 4. Predicting energy gap and electron affinity energy through TIM method

\begin{tabular}{|c|c|c|c|}
\hline Chemical Formula & ISI Index & $\mathrm{E}_{\text {Affinity }}(\mathrm{ev})$ & $\mathrm{E}_{\text {Gap }}(\mathrm{ev})$ \\
\hline $\mathrm{C}_{64} \mathrm{H}_{22}$ & 93 & 2.6287 & 0.8194 \\
\hline $\mathrm{C}_{72} \mathrm{H}_{24}$ & 105.2 & 2.8158 & 0.5168 \\
\hline $\mathrm{C}_{80} \mathrm{H}_{26}$ & 117.4 & 2.9823 & 0.2474 \\
\hline $\mathrm{C}_{88} \mathrm{H}_{28}$ & 129.6 & 3.1324 & 0.0047 \\
\hline
\end{tabular}

\section{Acknowledgements}

We would like to thank Islamic Azad University Central Tehran Branch (IAUCTB) for helpful protections.

\section{REFERENCES}

[1] R. Waser. Nanoelectronics and Information Technology, 3rd Edition, WILEY-VCH (2012).

[2] F. Patolsky, B.P. Timko, G. Zheng and C.M. Lieber. Nanowire-based nanoelectronic devices in the life sciences, MRS bulletin, Cambridge, Univ Press (2007).

[3] A.J. Pérez-Jiménez and J.C. Sancho-Garca. Conductance Enhancement in Nanographene-Gold Junctions by Molecular $\pi$-Stacking, Journal of the American Chemical Society, 131, 14857-14867 (2009). 
[4] J.C. Sancho-García and A.J. Pérez-Jiménez. Charge-Transport Properties of Prototype Molecular Materials for Organic Electronics Based on Graphene Nanoribbons, Physical Chemistry Chemical Physics, 11, 2741-2746 (2009).

[5] D. Jiang and S. Dai. Circumacenes versus Periacenes: HOMO-LUMO Gap and Transition from Nonmagnetic to Magnetic Ground State with Size, Chemical Physics Letters, $466,72-75$ (2008).

[6] S. Lias, Ionization Energy Evaluation, P.J. Linstrom and W.G. Mallard. NIST Chemistry WebBook, NIST Standard Reference Database Number 69, Eds., National Institute of Standards and Technology (2005).

[7] A.A. Khakpoor. Prediction Electronic and Physical Properties of Nano Structures; Topological Index Method, Int. J. of Adv. Res., 3, 6, 1536-1540 (2015).

[8] A.A. Khakpoor and B. Agahi Keshe. Electronic and Optical Properties of Nanostructures and Its Relationship with Harari Index , J. of Materials Science and Chemical Engineering, 3, 8 (2015).

[9] A.A. Khakpoor and B. Agahi Keshe. Some Electronic and Optical Properties of Nanostructures Using the First Zagreb Index, Int. J. of Adv. Res., 3, 5, 548-551 (2015).

[10] A.A. Khakpoor and B. Agahi Keshe. DETERMINATION OF PHYSICAL-CHEMICAL PROPERTIES OF TITANIUM ORGANIC COMPOUNDS USING TOPOLOGICAL INDICES; QSPR TECHNIQUES, International Journal of Current Research, 7, 5, 15686-15689 (2015).
[11] A.A. Khakpoor and B. Agahi Keshe. Physical and Electro-Optical Properties of Rylenes as Nanostructures Using Topological Indices Method, J. of Nanoelectronic and Optoelectronic, 11, 3, 280-283 (2016).

[12] A.A. Khakpoor. Total $\pi$ Electron Energy of Linear Acenes Nanostructure, International Letters of Chemistry, Physics and Astronomy, 64, 110-115 (2016).

[13] A.A. Khakpoor, B. Agahi Keshe and A. Agahi Kesheh. Prediction of Acenes Gibbs Energy using TIM, J. of Materials Science and Chemical Engineering, 3, 11 (2015).

[14] H. Wiener. Structural Determination of Paraffin Boiling Points, Journal of the American chemical Society, 69, 1, 17-20 (1947)

[15] N. Trinajstic. Chemical Graph Theory. 2nd Edition, CRC Press, Boca Raton (1992).

[16] G.S. Ezra. Symmetry Properties of Molecules, Lecture Notes in Chemistry, Springer, Germany (1982).

[17] Vukičević, D. and Gašperov, M. (2010) Bond Additive Modeling 1 Adriatic Indices, Croat. Chem. Acta., 83, 3, 243-260, (1376)

[18] E. S. Kadantsev, M. J. Stott and A. Rubio. Electronic Structure and Excitations in Oligoacenes from ab Initio Calculations, J. Chem. Phys. 124, 134901 (2006).

[19] G. Malloci, G. M ulas, G. Cappellini and C. Joblin. Time-Dependent Density Functional Study of the Electronic Spectra of Oligoacenes in the Charge States $-1,0,+1$, and +2 , Chem. Phys. 340, 43-58 (2007). 